OPEN ACCESS

Edited by:

Francesco Dieli,

Università degli Studi di Palermo,

Italy

Reviewed by:

John Anderson,

University College London,

United Kingdom

Elena Lo Presti,

Università degli Studi di Palermo,

Italy

${ }^{*}$ Correspondence:

Vito Pistoia

vito.pistoia@opbg.net;

Lorenzo Moretta

lorenzo.moretta@opbg.net

Specialty section: This article was submitted to

T Cell Biology,

a section of the journal

Frontiers in Immunology

Received: 31 January 2018 Accepted: 20 April 2018

Published: 07 May 2018

Citation:

Pistoia V, Tumino N, Vacca P, Veneziani I, Moretta A, Locatelli F and Moretta L (2018) Human $\gamma \delta$ T-Cells:

From Surface Receptors to the

Therapy of High-Risk Leukemias.

Front. Immunol. 9:984.

doi: 10.3389/fimmu.2018.00984

\title{
Human $\gamma \delta$ T-Cells: From Surface Receptors to the Therapy of High-Risk Leukemias
}

\begin{abstract}
Vito Pistoia ${ }^{1 *}$, Nicola Tumino ${ }^{1}$, Paola Vacca ${ }^{1}$, Irene Veneziani ${ }^{1}$, Alessandro Moretta ${ }^{2}$, Franco Locatelli ${ }^{3,4}$ and Lorenzo Moretta ${ }^{1 *}$

${ }^{1}$ Immunology Area, IRCCS Bambino Gesù Pediatric Hospital, Rome, Italy, ${ }^{2}$ Dipartimento di Medicina Sperimentale and Centro di Eccellenza per le Ricerche Biomediche, Università degli Studi di Genova, Genoa, Italy, ${ }^{3}$ Department of Onco-Hematology and Cell and Gene Therapy, IRCCS Bambino Gesù Pediatric Hospital, Rome, Italy, ${ }^{4}$ Department of Pediatric Science, University of Pavia, Pavia, Italy
\end{abstract}

$\gamma \delta T$ lymphocytes are potent effector cells, capable of efficiently killing tumor and leukemia cells. Their activation is mediated by $\gamma \delta$ T-cell receptor (TCR) and by activating receptors shared with NK cells (e.g., NKG2D and DNAM-1). $\gamma \delta$ T-cell triggering occurs upon interaction with specific ligands, including phosphoantigens (for $\mathrm{V} \gamma 9 \mathrm{~V} \delta 2 \mathrm{TCR}$ ), MICA-B and UL16 binding protein (for NKG2D), and PVR and Nectin-2 (for DNAM-1). They also respond to cytokines undergoing proliferation and release of cytokines/chemokines. Although at the genomic level $\gamma \delta$ T-cells have the potential of an extraordinary TCR diversification, in tissues they display a restricted repertoire. Recent studies have identified various $\gamma \delta$ TCR rearrangements following either hematopoietic stem cell transplantation (HSCT) or cytomegalovirus infection, accounting for their "adaptive" potential. In humans, peripheral blood $\gamma \delta$ T-cells are primarily composed of $\vee_{\gamma} 9 \mathrm{~V} \delta 2$ chains, while a minor proportion express $\mathrm{V} \delta 1$. They do not recognize antigens in the context of $\mathrm{MHC}$ molecules, thus bypassing tumor escape based on MHC class I downregulation. In view of their potent antileukemia activity and absence of any relevant graft-versus-host disease-inducing effect, $\gamma \delta$ T-cells may play an important role in the successful clinical outcome of patients undergoing HLA-haploidentical HSCT depleted of TCR $\alpha \beta$ T/CD19+ $B$ lymphocytes to cure high-risk acute leukemias. In this setting, high numbers of both $\gamma \delta$ T-cells (Vס1 and V82) and NK cells are infused together with CD34+ HSC and may contribute to rapid control of infections and leukemia relapse. Notably, zoledronic acid potentiates the cytolytic activity of $\gamma \delta$ T-cells in vitro and its infusion in patients strongly promotes $\gamma \delta$ T-cell differentiation and cytolytic activity; thus, treatment with this agent may contribute to further improve the patient clinical outcome after HLA-haploidentical HSCT depleted of TCR $\alpha \beta$ T/CD19+ B lymphocytes.

Keywords: $\gamma \delta$ T-cells, receptors, hematopoietic stem cells, HLA-haploidentical transplantation, $\alpha \beta$ T-cell, B-cell depletion

\section{GENERAL FEATURES OF HUMAN $\gamma \delta$ T-CELLS}

$\gamma \delta$ T-cells straddle the innate and adaptive arms of the immune system and are involved in response to pathogens [e.g., mycobacteria; cytomegalovirus (CMV)] and tumors. Similar to $\alpha \beta$ T-cells, $\gamma \delta$ T-cells develop in the thymus, but express a rearranged T-cell receptor (TCR) consisting of a TCR- $\gamma$ and a TCR- $\delta$ chain (1). Although important information has been obtained by studies in mice, this review will be focalized on human $\gamma \delta$ T-cells (2). Four human $\gamma \delta$ T-cell populations can be identified 


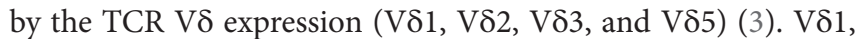
$\mathrm{V} \delta 2, \mathrm{~V} \delta 3$, and $\mathrm{V} \gamma 2, \mathrm{~V} \gamma 3, \mathrm{~V} \gamma 4, \mathrm{~V} \gamma 5, \mathrm{~V} \gamma 8, \mathrm{~V} \gamma 9$, and $\mathrm{V} \gamma 11$ are the most frequently gene segments used in rearrangement of $\delta$ and $\gamma$ chains, respectively (4). In humans, most peripheral blood $\gamma \delta$ T-cells express V82 TCR chain paired with V $\gamma 9$ chain (5), while $\gamma \delta$ T-cells expressing V81 or V83 TCR chain can be paired with various $\mathrm{V} \gamma$ chains (6) and they are predominant in epithelial tissues of skin, lungs, intestine and reproductive tract (7), liver, spleen, and thymus (8). $\gamma \delta$ T-cells with $\mathrm{V} \gamma 4 \mathrm{~V} \delta 5$ TCR are able to bind the endothelial protein $\mathrm{C}$ receptor (9). Moreover, four subsets of

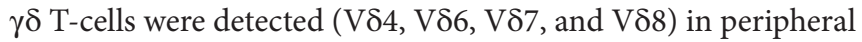
blood of patients with B-cell non-Hodgkin lymphoma, but the $\gamma$ chain pairings are still unknown. Although the majority of $\gamma \delta$ T-cells do not express either CD4 or CD8, there is a small percentage of $\gamma \delta$ T-cells that are CD8 positive (8). Different mechanisms of TCR rearrangement occur in mouse immune system (2).

The major pathways of $\gamma \delta$ T-cell activation involve triggering of the $\gamma \delta$ TCR that, at variance with $\alpha \beta$ T-cells, does not recognize peptides presented by antigen-presenting cells (APCs) in the context of the MHC. The $\gamma \delta$ TCR may bind soluble or membrane proteins, such as tetanus toxoid (10), bacterial proteins (11), viral proteins (2), and heat shock proteins. Moreover, the $\gamma \delta$ TCR may bind CD1d expressed by professional antigen presenting cells (APCs), presenting glycolipids and microbial lipids (12).

In adult human, $\gamma \delta$ T-cell population represents $1-5 \%$ of all $\mathrm{CD}^{+}$cells. In peripheral blood of healthy human subjects, T-cells expressing V $\gamma 9 \mathrm{~V} \delta 2$ TCR can account for up 95\% of $\gamma \delta$ T-cells (10) and render between 1 and $10 \%$ of all blood T-cells (2). Conversely, V $\delta 1 \mathrm{~T}$-cells represents only $10-30 \%$ of $\gamma \delta \mathrm{T}$-cells in peripheral blood of healthy human (10). In the lymphoid tissue and in the gut- and skin- associated lymphoid systems, $\gamma \delta$ T-cells show a frequency similar to that detected in peripheral blood (11). V $\gamma 9$ V 82 T-cells are activated $(13,14)$ by natural metabolites known as phosphoantigens (PhAgs), such as isopentenyl pyrophosphate (IPP), produced in eukaryotes through the mevalonate pathway involved in cholesterol synthesis and protein prenylation (15). A dysregulated mevalonate pathway leading to overproduction of endogenous IPP occurs in transformed cells $(16,17)$. The endogenous production of IPP and related pyrophosphates and the consequent ability of a given cell type to activate $\gamma \delta$ T-cells can be pharmacologically manipulated. A critical enzyme in the mevalonate pathway is farnesyl pyrophosphate synthase (FPPS), which acts downstream of IPP production. Targeted knockdown of FPPS leads to accumulation of IPP and subsequent activation of $\gamma \delta$ T-cells (18). Treatment of tumor cells or monocytes with the bisphosphonate zoledronic acid (ZOL), which blocks FPPS function, leads to increased IPP production, and thereby induces selective activation of $\mathrm{V} \gamma 9 \mathrm{~V} \delta 2 \mathrm{~T}$-cells $(17,19,20)$. Until recently, it was unclear how the V $\gamma 9 \mathrm{~V} \delta 2$ TCR could recognize PhAgs. This enigma has been clarified by the discovery that butyrophilin $3 \mathrm{~A} 1$ (also known as CD277) plays an essential role in the interaction of PhAgs with the V $\gamma 9 \mathrm{~V} \delta 2 \mathrm{TCR}$, although the fine mechanisms of the phenomenon are still to be fully elucidated $(4,21)$.

Upon activation, $\gamma \delta$ T-cells can produce large amounts of Th1 cytokines, such as IFN $\gamma$ and $\mathrm{TNF} \alpha$, and directly induce monocyte-derived dendritic cell maturation and activation, suggesting a potential adjuvant role of this cross-talk in enhancing antigen-specific $\alpha \beta$ T-cell response $(12,13)$. In this respect, it has been reported that $\gamma \delta$ T-cells may take up and process soluble proteins inducing proliferation, cytokine production and cytotoxicity by $\mathrm{CD}^{+} \alpha \beta^{+}$T-cells (22).

The ability of $\gamma \delta$ T-cells to kill hematological and solid tumors and to release Th1-type cytokines, combined with the possibility of growing these cells in culture, has attracted great interest for their use as adoptive cell therapy of cancer. Emphasis has been placed on V V $9 \mathrm{~V} \delta 2$ T-cells, which are easily expanded in vitro by $\mathrm{PhAg}$ stimulation (induced by exposure of cells to ZOL) and can be further boosted in vivo with ZOL or other synthetic PhAgs. Several clinical trials of $\mathrm{V} \gamma 9 \mathrm{~V} \delta 2 \mathrm{~T}$-cell-based immunotherapy for both hematological malignancies (23-26) and solid tumors (27-32) have been conducted with promising results. A note of caution on the efficacy of these approaches comes from the plasticity of $\gamma \delta$ T-cells controlled by the signals from the microenvironment, which can switch the antitumor profile of these cells to a tumor-promoting one, for example through induction of IL-17 production (33).

\section{$\gamma \delta$ T-CELLS: RECEPTORS AND LIGANDS}

A feature typical of NK cells shared by $\gamma \delta$ T-cells is the ability to kill malignant and infected cells in the absence of any prior exposure. Moreover, $\gamma \delta$ T-cells share with NK cells the expression of different NK receptors (NKRs), such as the NK activating receptor DNAM-1, the Fc receptor CD16, and the C-type lectin-like receptor NKG2D (34). Tumor cell recognition and the associated $\gamma \delta$ T-cells activation require the engagement of the TCR and/or NKRs, mostly NKG2D. NKG2D binds MHC class I polypeptiderelated sequence MICA, MICB, and UL16 binding proteins (ULBPs) expressed on stressed and tumor cells. Overexpression of the NKG2D ligands ULBP1 and ULBP4 (35) by hematological and epithelial tumors, respectively, drives efficient cytotoxic responses by $\mathrm{V} \gamma 9 \mathrm{~V} \delta 2 \mathrm{~T}$-cells. The proteins that can induce V $\delta 1$ activation are incompletely known, although CD1c and CD1d, members of CD1 family, can activate V $\delta 1$ T-cells through TCR binding (36). V $\delta 1$ T-cells of the human intestinal epithelium are able to recognize MICA and MICB ligands, by the synergistic actions of TCR and NKG2D. Moreover, in Vס1 T-cells subset, the interaction of NKp30 with B7-H6, expressed on tumor cells, allows a specific antitumor activity (9). Both TCR and NKG2D bound overlapping fragments of MICA, with different affinity and kinetics, the affinity of NKG2D being by far superior to that of TCR (37). The TCR-MICA complex was particularly stable, suggesting a sequential model, whereby the initial binding of NKG2D is followed by the formation of the more stable TCR-MICA complex. MICA engagement by TCR was found to be indispensable for $\gamma \delta$ T-cell-mediated cytotoxicity, while NKG2D played a co-stimulatory role (38). ULBP molecules may be recognized in a similar manner, as it has been shown that ULBP4 engages both NKG2D, and V $\gamma 9$ V 82 TCR. DNAM-1, another NKR involved in activation of $\mathrm{V} \gamma 9 \mathrm{~V} \delta 2 \mathrm{~T}$-cells, binds its ligand nectin-like 5 on tumor cells rapidly triggering the cytotoxic activity of $\mathrm{V} \gamma 9 \mathrm{~V} \delta 2 \mathrm{~T}$-cells (39). Controversial results have been reported regarding the expression and function of NKp44 on a minor subset (less than $10 \%)$ of $\gamma \delta$ T-cells after culture in the presence of IL-15 (40). In addition, some $\gamma \delta$ T-cells may express the HLA-E-specific CD94/NKG2A 
inhibitory receptor. Thus, following interaction with HLA-E ${ }^{+}$ cells, the functional activity of these cells may be modulated, as reported in the case of $\gamma \delta$ T-cells interacting with enterocytes (41). The sequential recognition of different targets by $\gamma \delta$ T-cells could play an important role in immunosurveillance, as it allows the latter cells to rapidly scan target cells for stress markers indicative of possible infection or malignant transformation. The requirement for a multicomponent stress context for full $\gamma \delta$ T-cell activation could then provide fail-safe protection against autoimmunity. The apparent co-existence of diverse co-stimulatory axes decreases the chances of immune evasion. The main interactions between $\gamma \delta$ T-cells and tumor cells are shown in Figure 1.

\section{$\gamma \delta$ T-CELLS AND HEMATOPOIETIC STEM CELL TRANSPLANTATION (HSCT)}

The role of $\gamma \delta$ T-cells in HSCT has been the subject of numerous studies in the last three decades (Figure 2). After initial reports with contrasting results (42-44), it was demonstrated that 5-year disease-free and overall survival of leukemia patients who received HLA-mismatched allo-HSCT depleted of TCR $\alpha \beta$ T-cells correlated significantly with high number of $\gamma \delta$ T-cells circulating in patient peripheral blood after transplantation (45-47). It was proposed that $\gamma \delta$ T-cells, recovering after the allograft, play a relevant role in the graft-versus-leukemia $(\mathrm{GvL})(46)$, albeit other studies have highlighted the prominent GvL activity of NK cells in T-cell-depleted HSCT $(48,49)$. Analysis of the TCR V $\delta$ repertoire revealed that circulating V $\delta 1$ cells are predominant in patients with high $\gamma \delta$ T-cells counts, whereas patients with low $\gamma \delta$ T-cells counts and healthy individuals display mostly V $\delta 2$ cells (46).

A study carried out at a single institution investigated the clinical impact of $\gamma \delta$ T-cell reconstitution in 102 consecutive pediatric patients with acute leukemia given allogeneic HSCT from different donors and employing different cell sources (50). A major finding was that the probability of infections in patients with high counts of circulating $\gamma \delta$ T-cells after the allograft was significantly lower than that in patients with low or normal counts of $\gamma \delta$ T-cells. In particular, no bacterial infection occurred in the former patient group. Furthermore, also event-free survival of patients with high numbers of circulating $\gamma \delta$ T-cells after HSCT was significantly better than that of patients with low or normal numbers of $\gamma \delta$ T-cells (50).

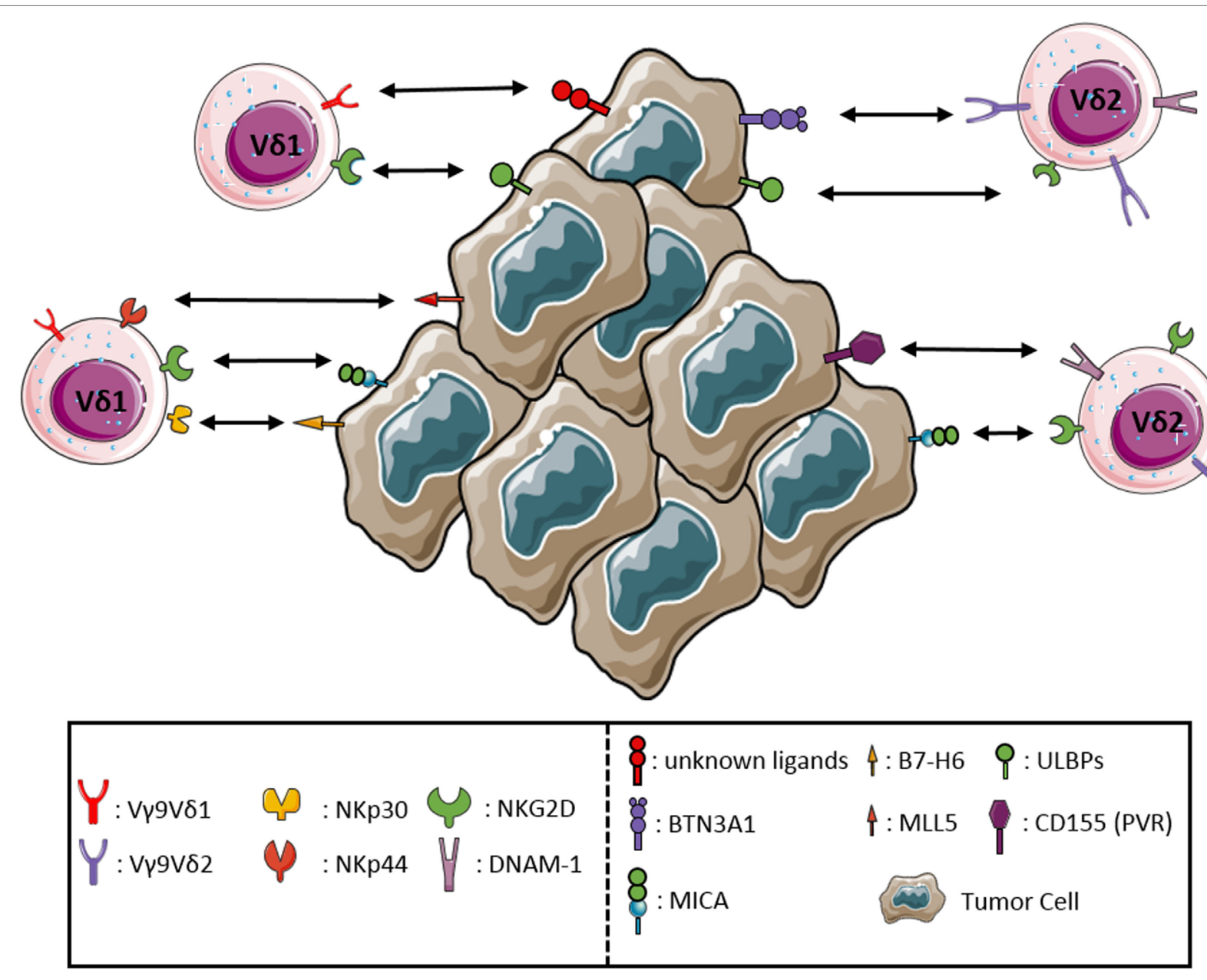

FIGURE 1 | Receptor-ligand interactions between $\gamma \delta$ T lymphocytes and tumor cells. The major interactions occurring between the activating receptors expressed by $\gamma \delta \mathrm{T}$ lymphocytes and the corresponding ligands either de novo expressed or upregulated by tumor cells are represented in detail. 


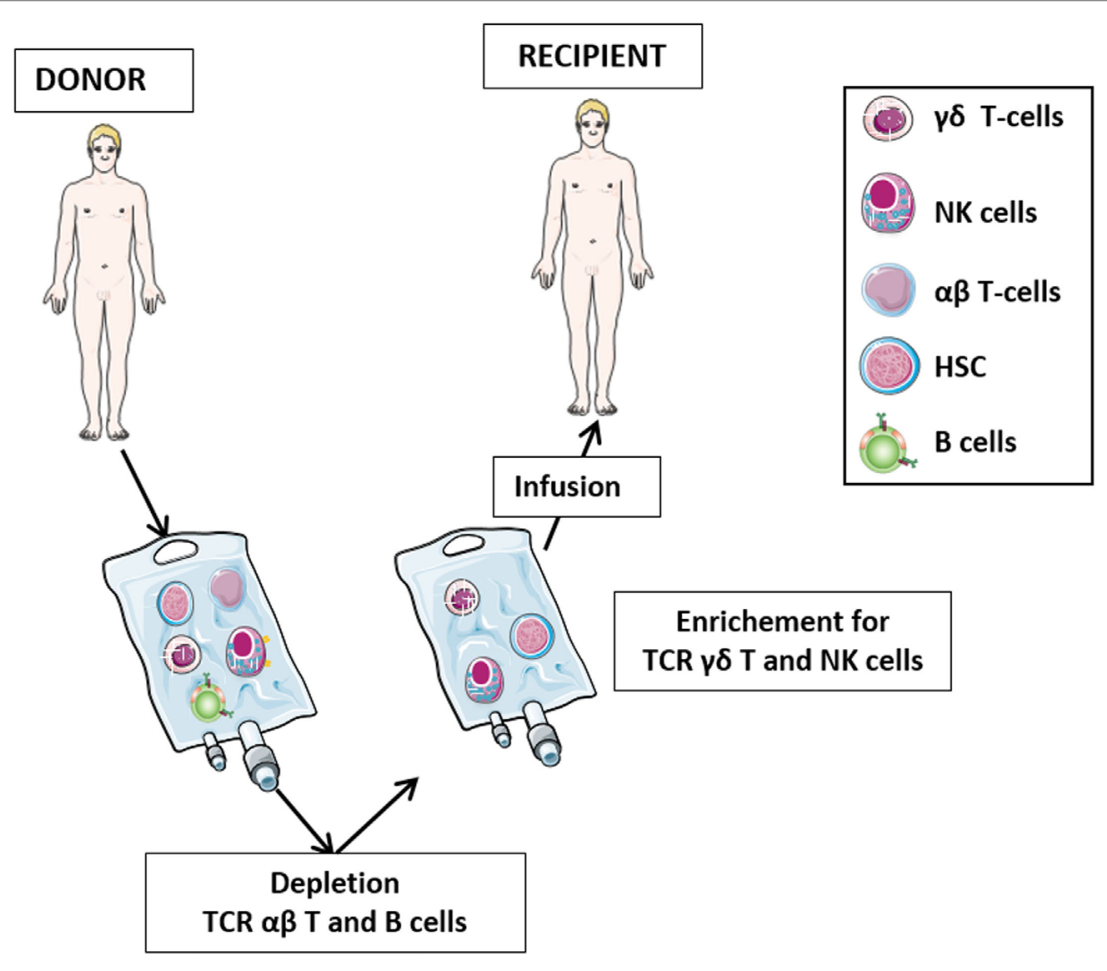

FIGURE 2 | The protocol of T-cell receptor (TCR) $\alpha \beta$ T-cell and B-cell depletion recently developed in haplo-HSC transplantation. The protocol for haplo-HSCT allows infusion of donor HSC, together with high number of $\gamma \delta \mathrm{T}$ lymphocytes and NK cells. This novel strategy permits, during the early posttransplant period (6-8 weeks), a better control of leukemia cells escaping the preparative regimen, thus preventing disease relapses. In this transplantation setting, in addition to $\gamma \delta$ T-cells and NK cells developing late from donor HSC, these promptly available effectors transferred with the graft may immediately exert their graft-versus-leukemia effect and contribute to the control of infections.

It is still a matter of debate whether $\gamma \delta$ T-cell regeneration in HSCT recipients occurs either via the peripheral expansion of mature donor T-cells present in the graft or through a differentiation process from donor HSC. Using polymerase chain reaction-based complementarity-determining region (CDR)3 spectratyping and DNA sequencing for TCR $\delta$ chains, it was initially shown that the size distribution patterns of CDR3 were recovered a few months after allo-HSCT and that such recovery was faster than that of $\alpha \beta \mathrm{T}$-cells (51). Clonal predominance of TCR V $\delta 1^{+}$cells occurred after transplantation in a few patients, and follow-up of a donor-recipient pair supported the hypothesis that peripheral expansion of mature donor T-cells contained in the graft was the main pathway of $\gamma \delta \mathrm{T}$-cell regeneration after alloHSCT (51). More recently, a study has evaluated human $\gamma \delta$ T-cell reconstitution using an RNA and cDNA-based next generation sequencing (NGS) approach that has allowed the investigation at the clonal level of TCR $\gamma$ and $\delta$ chain (TRG and TRD) repertoires in sorted $\gamma \delta$ T-cells before and after allo-HSCT (52). In the absence of CMV reactivation, such repertoires developed after 30-60 days from allo-HSCT and remained stable over at least 6 months. TRG and TRD repertoires after transplantation were qualitatively comparable to those present before transplantation, but contained clonotypes different from those found in the donor, suggesting that they were generated de novo from donor HSC through a process of cell maturation. In addition, reactivation of CMV caused massive perturbations of TRG and TRD repertoires, being associated with preferential proliferation and expansion of a few individual V81 and V83 T-cell clones. Taken together, these studies indicate that $\gamma \delta \mathrm{T}$-cells are capable of adaptive responses generating different TRG and TRD repertoires and different clonal expansions $(51,52)$.

\section{$\gamma \delta$ T-CELLS AND $\alpha \beta$ T-CELL-DEPLETED HLA-HAPLOIDENTICAL HSCT}

Hematopoietic stem cell transplantation from an HLAhaploidentical relative (haplo-HSCT) provides most patients lacking a suitable matched donor with the chance of undergoing transplantation. Clinical development of haplo-HSCT has been boosted by the demonstration that extensive T-cell depletion from the graft efficiently prevents both acute and chronic graftversus-host disease (GvHD), even when the donor and the recipient were mismatched for an entire HLA haplotype $(53,54)$. The therapeutic efficacy of T-cell-depleted haplo-HSCT largely depends on donor NK cells either generated from HSC or infused with the graft mediating a potent GvL effect (55-58). Such effect is delayed in patients transplanted with positively selected donor $\mathrm{CD}_{4}{ }^{+}$cells, since the first wave of killer-immunoglobulin-like receptor-positive, alloreactive NK cells, differentiating from infused HSC appears after a minimum time interval of 6-8 weeks $(49,56,59,60)$. The delayed availability of mature NK cells, 
mainly responsible of GvL effect, explains, at least in part, the transplant-related mortality and the early leukemic relapses, particularly in acute myeloid leukemia (AML). To circumvent this problem, a novel strategy of graft manipulation has been set up, whereby both T-cells bearing the $\alpha \beta$ T-cell receptor (TCR) and $\mathrm{CD} 19^{+} \mathrm{B}$ lymphocytes are depleted from the graft before infusion $(61,62)$. This approach abates TCR $\alpha \beta$ T-cell-mediated GvHD, prevents Epstein-Barr virus-driven B cell lymphoproliferative disorders occurring in immunocompromised patients, and allows to transfer to the recipient high numbers of haploidentical $\mathrm{CD}_{3} 4^{+}$cells and of mature NK cells and TCR $\gamma \delta$ T-cells, which can readily exert protective functions against leukemia cell regrowth and life-threatening infections (63-66). Notably, TCR $\gamma \delta$ T-cells and NK cells share a number of features that are relevant in the haplo-HSCT setting. Both cell types: (i) kill tumor cells in a MHC-independent manner (34), (ii) are involved in anti-CMV immune responses (67), (iii) do not mediate GvHD, since they do not recognize peptide antigens presented in the context of MHC (12), (iv) interact with each other and with additional immune cells, such as $\alpha \beta$ T-cells and dendritic cells (12), and (v) following activation, are cytotoxic to mesenchymal stromal cells, a major component of tumor microenviroment (68).

We have recently investigated $\gamma \delta$ T-cell reconstitution after haplo-HSCT depleted of TCR $\alpha \beta^{+}$T/CD $19^{+}$B cells (Figure 2) in 27 children, 15 of whom had leukemia and 12 primary immune-deficiencies or bone marrow failure syndromes (63). Immunophenotypic characterization of peripheral blood mononuclear cells performed at 1, 3, and 6 months after transplantation showed an initial predominance of $\gamma \delta$ over $\alpha \beta$ T-cells, followed by progressive recovery of the latter cells. $\gamma \delta$ T-cells included three different populations, i.e., $\mathrm{V} \delta 2, \mathrm{~V} \delta 1$ and, at a lower extent, V $\delta 2^{-}, \mathrm{V} \delta 1^{-}$(63). Four subsets of human $\gamma \delta \mathrm{T}$-cells have been identified based upon the expression of the CD45 and $\mathrm{CD} 27$ surface markers: naïve $\left(\mathrm{CD} 45 \mathrm{RA}^{+}, \mathrm{CD} 27^{+}\right)$, central memory $\left(\mathrm{CM}: \mathrm{CD} 45 \mathrm{RA}^{-}, \mathrm{CD}^{+} 7^{+}\right.$), effector memory (EM: CD45RA-, $\mathrm{CD}_{27}{ }^{-}$), and terminally differentiated (EMRA: CD45RA ${ }^{+}$, $\left.\mathrm{CD}_{27^{-}}\right)(69,70)$. Similar to the corresponding $\alpha \beta$ T-cell subsets, naïve and $\mathrm{CM} \gamma \delta \mathrm{T}$-cells express lymph-node homing receptors and are devoid of immediate effector functions. In contrast, EM and EMRA $\gamma \delta$ T-cells express receptors for migration to inflamed tissue where they mediate effector functions, such as cytotoxicity and cytokine production (70). Studies carried out on Vy9V82 T-cells have demonstrated that PhAg-stimulated naïve cells generate TCM cells, while cytokine-stimulated TCM cells differentiate into TEM or TEMRA in the absence of antigen (69). Notably, TEMRA V $\gamma 9 \mathrm{~V} \delta 2$ T-cells are the major subset endowed with potent antitumor and antibacterial activity (69). Analysis of the differentiation status of $\gamma \delta$ T-cells in our patients given haplo-HSCT showed that TCM cells were predominant in both V $\delta 2$ and V $\delta 1$ cells. The relative proportions of the different V $\delta 2$ and V $\delta 1$ subsets remained stable over time and were similar to those detected in the donor. Naïve V82 cells increased significantly between 20 days and 3 months after haplo-HSCT, suggesting that circulating $\gamma \delta$ T-cells in transplanted patients consisted of not only mature cells derived from the graft, but also of cells differentiating from donor HSC (63). Investigation of TRG and TRD repertoires in recipients of haplo-HSCT depleted of TCR $\alpha \beta^{+} \mathrm{T}$ and $\mathrm{CD} 19^{+}$cells using powerful NGS techniques will shed new light on the origin of $\gamma \delta$ T-cells in this setting.

Studies performed in solid organ transplantation and HSCT recipients have demonstrated that a remarkable expansion of $\mathrm{V} \delta 2^{-}$ $\gamma \delta$ T-cells displaying a TEMRA immunophenotype and exerting cytotoxic function takes place in the course of CMV infection (67). The investigation of the $\gamma \delta$ TCR junctional diversity revealed the expansion of V $\delta 1$ and V $83 \mathrm{~T}$-cells with a restricted repertoire during CMV infection (67). The mechanism whereby V $\delta 2-\gamma \delta$ T-cells recognize CMV-infected cells involves $\gamma \delta$ TCR, still incompletely defined co-stimulatory molecules including LFA-1, and different $\gamma \delta$ TCR ligands expressed by virus-infected cells (67). One of such ligands is the recently identified MHC-related molecule endothelial protein C receptor (71). CMV-induced V $\delta 2$ $\gamma \delta$ T-cells are able to recognize and kill hematological tumor cell lines and primary AML blasts $(72,73)$. Consistently with these notions, our patients who experienced CMV reactivation displayed a significant expansion of the V $\delta 1 \mathrm{~T}$-cell subset with a cytotoxic TEMRA phenotype, which was absent in patients without CMV reactivation. These CMV-driven V $\delta 1$ T-cells killed in vitro primary acute lymphoblastic leukemia and AML blasts more efficiently than V $\delta 1 \mathrm{~T}$-cells from patients that did not reactivate CMV infection, suggesting that CMV infection promotes both expansion and activation of V81 T-cells (63).

\section{EFFECT OF ZOLEDRONIC ACID ON $\gamma \delta$ T-CELLS RECOVERING AFTER $\alpha \beta$ T-CELL- DEPLETED HLA-HAPLOIDENTICAL HSCT}

We demonstrated that V82 T-cells from patients who received haplo-HSCT depleted of TCR $\alpha \beta^{+}$and $\mathrm{CD} 19^{+}$cells expanded in vitro upon incubation with $\mathrm{ZOL}$, which promoted the acquisition of an EM phenotype and potentiated the cytotoxic activity against primary leukemic blasts. Such activity was dependent on the levels of PhAgs expressed by leukemia cells and on TCR $\mathrm{V} \gamma 9$ mediated recognition of the latter cells (63). Indeed, the lytic capacity of $\gamma \delta$ T-cells was strongly enhanced by sensitizing leukemic target cells with ZOL. These in vitro results provided the rationale to investigate in a subsequent clinical study the effect of ZOL infusion in 43 pediatric recipients of haplo-HSCT depleted of TCR $\alpha \beta^{+}$and CD $19^{+}$cells (74). ZOL was infused every 28 days at least twice in most patients. Such treatment was safe and well tolerated, and, when administered three or more times, reduced GvHD occurrence and improved overall survival. The first treatment with ZOL induced the differentiation of V $\delta 2$ T-cells, which switched from a CM to an EM/EMRA phenotype. Such maturation correlated with increased V82 cell-mediated cytotoxicity against primary leukemia cells irrespective of their PhAg expression. Proteomic analyses identified an anti-proliferative effect of infused ZOL on total $\gamma \delta$ T-cells that was consistent with the decrease of V82 T-cells starting 3 months after HSCT. Such effect was already evident after the first ZOL infusion and it was further boosted by the subsequent infusions. In contrast, the percentage of V81 T-cells increased during ZOL infusions irrespective of CMV reactivation (74). Altogether, these results suggest that haplo-HSCT transplanted pediatric patients may benefit from ZOL treatment. 


\section{CONCLUSION}

Similar to NK cells, $\gamma \delta$ T-cells are endowed with antileukemia and anti-infection potential and do not mediate GvHD. These features are particularly useful in the setting of haplo-HSCT depleted of TCR $\alpha \beta^{+}$T and CD19+ B cells, since the graft infused into the patient is highly enriched in mature $\gamma \delta$ and NK cells ready to exert their effector functions. Both V $\delta 2$ and V $\delta 1 \gamma \delta$ T-cells are cytotoxic toward primary acute leukemia cells, while V $\delta 1$ and V83 cells undergo adaptive clonal expansions driven by CMV reactivation that are reminiscent of antigen-specific $\alpha \beta$ T-cells responses. Pharmacological manipulation, for example, through ZOL administration, may potentiate the anti-leukemic activity of endogenous $\mathrm{V} \delta 2 \mathrm{~V} \gamma 9 \mathrm{~T}$-cells; if this effect translates into a significant benefit for the patients awaits to be definitively proved in prospective controlled clinical trials. Future studies aimed at deconvoluting the fine mechanisms whereby $\gamma \delta$ T-cells recognize malignant and virus-infected cells will help improve the therapeutic potential of $\gamma \delta$ T-cells in the setting of haplo-HSCT.

\section{AUTHOR CONTRIBUTIONS}

All authors discussed together the general outline of the article. VP, NT, and LM wrote the first draft that was subsequently

\section{REFERENCES}

1. Prinz I, Silva-Santos B, Pennington DJ. Functional development of gammadelta T cells. Eur J Immunol (2013) 43(8):1988-94. doi:10.1002/eji.201343759

2. Sciammas R, Tatsumi Y, Sperling AI, Arunan K, Bluestone JA. TCR gamma delta cells: mysterious cells of the immune system. Immunol Res (1994) 13(4):268-79. doi:10.1007/BF02935618

3. Zhao Y, Niu C, Cui J. Gamma-delta (gammadelta) T cells: friend or foe in cancer development? J Transl Med (2018) 16(1):3. doi:10.1186/s12967-017-1378-2

4. Adams EJ, Gu S, Luoma AM. Human gamma delta T cells: evolution and ligand recognition. Cell Immunol (2015) 296(1):31-40. doi:10.1016/j. cellimm.2015.04.008

5. Braza MS, Klein B, Fiol G, Rossi JF. Gammadelta T-cell killing of primary follicular lymphoma cells is dramatically potentiated by GA101, a type II glycoengineered anti-CD20 monoclonal antibody. Haematologica (2011) 96(3):400-7. doi:10.3324/haematol.2010.029520

6. Thedrez A, Sabourin C, Gertner J, Devilder MC, Allain-Maillet S, Fournie JJ, et al. Self/non-self discrimination by human gammadelta T cells: simple solutions for a complex issue? Immunol Rev (2007) 215:123-35. doi:10.1111/j.1600-065X.2006.00468.x

7. Carding SR, Egan PJ. Gammadelta T cells: functional plasticity and heterogeneity. Nat Rev Immunol (2002) 2(5):336-45. doi:10.1038/nri797

8. Bonneville M, O’Brien RL, Born WK. Gammadelta T cell effector functions: a blend of innate programming and acquired plasticity. Nat Rev Immunol (2010) 10(7):467-78. doi:10.1038/nri2781

9. Wu D, Wu P, Qiu F, Wei Q, Huang J. Human gammadeltaT-cell subsets and their involvement in tumor immunity. Cell Mol Immunol (2017) 14(3):245-53. doi:10.1038/cmi.2016.55

10. Kozbor D, Trinchieri G, Monos DS, Isobe M, Russo G, Haney JA, et al. Human TCR-gamma+/delta+, CD8+ T lymphocytes recognize tetanus toxoid in an MHC-restricted fashion. J Exp Med (1989) 169(5):1847-51. doi:10.1084/ jem.169.5.1847

11. Rust CJ, Koning F. Gamma delta T cell reactivity towards bacterial superantigens. Semin Immunol (1993) 5(1):41-6. doi:10.1006/smim.1993.1006

12. Vantourout P, Hayday A. Six-of-the-best: unique contributions of gammadelta T cells to immunology. Nat Rev Immunol (2013) 13(2):88-100. doi:10.1038/ nri3384 reviewed by PV, IV, AM, and FL. Thereafter, all authors contributed to the elaboration of the final version of the manuscript.

\section{ACKNOWLEDGMENTS}

While this manuscript was under revision, AM passed away on February 17, 2018. His seminal discoveries of KIRs and NCR, as well as important studies on human NK cell pathophysiology, represent true milestones not only in Immunology but, more generally, in Medicine. Indeed, the unthinkable clinical outcome of patients with otherwise fatal high-risk leukemia in the haploidentical HSCT setting stem mostly from AM's discoveries. We are missing his invaluable scientific insight and, even more, his uncommon humanity, irony, and smile. We are dedicating this contribution to the memory of AM, an unforgettable friend and outstanding scientist.

\section{FUNDING}

Supported by grants awarded by Associazione Italiana Ricerca per la Ricerca sul Cancro (AIRC)-352 Special Project " $5 \times 1000$ Molecular Clinical Oncology Extension Program" no. 9962 (AM, LM, and FL); IG 2017 project no. 20312 (AM); IG 2017 project no. 17273 (VP); and IG 2014 project no. 15283 (LM).

13. Kabelitz D, Glatzel A, Wesch D. Antigen recognition by human gammadelta T lymphocytes. Int Arch Allergy Immunol (2000) 122(1):1-7. doi:10.1159/ 000024353

14. Chien YH, Meyer C, Bonneville M. Gammadelta T cells: first line of defense and beyond. Annu Rev Immunol (2014) 32:121-55. doi:10.1146/ annurev-immunol-032713-120216

15. Gruenbacher G, Nussbaumer O, Gander H, Steiner B, Leonhartsberger N, Thurnher M. Stress-related and homeostatic cytokines regulate Vgamma9Vdelta2 T-cell surveillance of mevalonate metabolism. Oncoimmunology (2014) 3(8):e953410. doi:10.4161/21624011.2014.953410

16. Tanaka Y, Morita CT, Tanaka Y, Nieves E, Brenner MB, Bloom BR. Natural and synthetic non-peptide antigens recognized by human gamma delta $\mathrm{T}$ cells. Nature (1995) 375(6527):155-8. doi:10.1038/375155a0

17. Gober HJ, Kistowska M, Angman L, Jeno P, Mori L, De Libero G. Human $\mathrm{T}$ cell receptor gammadelta cells recognize endogenous mevalonate metabolites in tumor cells. J Exp Med (2003) 197(2):163-8. doi:10.1084/jem.20021500

18. Li J, Herold MJ, Kimmel B, Muller I, Rincon-Orozco B, Kunzmann V, et al. Reduced expression of the mevalonate pathway enzyme farnesyl pyrophosphate synthase unveils recognition of tumor cells by Vgamma9Vdelta2 T cells. J Immunol (2009) 182(12):8118-24. doi:10.4049/jimmunol.0900101

19. Roelofs AJ, Jauhiainen M, Monkkonen H,Rogers MJ,MonkkonenJ, Thompson K Peripheral blood monocytes are responsible for gammadelta $\mathrm{T}$ cell activation induced by zoledronic acid through accumulation of IPP/DMAPP. Br J Haematol (2009) 144(2):245-50. doi:10.1111/j.1365-2141.2008.07435.x

20. Wang H, Sarikonda G, Puan KJ, Tanaka Y, Feng J, Giner JL, et al. Indirect stimulation of human Vgamma2Vdelta2 $\mathrm{T}$ cells through alterations in isoprenoid metabolism. J Immunol (2011) 187(10):5099-113. doi:10.4049/ jimmunol.1002697

21. Vavassori S, Kumar A, Wan GS, Ramanjaneyulu GS, Cavallari M, El Daker S, et al. Butyrophilin 3A1 binds phosphorylated antigens and stimulates human gammadelta T cells. Nat Immunol (2013) 14(9):908-16. doi:10.1038/ni.2665

22. Brandes M, Willimann K, Bioley G, Levy N, Eberl M, Luo M, et al. Crosspresenting human gammadelta $\mathrm{T}$ cells induce robust CD8+ alphabeta $\mathrm{T}$ cell responses. Proc Natl Acad Sci U S A (2009) 106(7):2307-12. doi:10.1073/ pnas.0810059106

23. Abe Y, Muto M, Nieda M, Nakagawa Y, Nicol A, Kaneko T, et al. Clinical and immunological evaluation of zoledronate-activated Vgamma9gammadelta 
T-cell-based immunotherapy for patients with multiple myeloma. Exp Hematol (2009) 37(8):956-68. doi:10.1016/j.exphem.2009.04.008

24. Kunzmann V, Smetak M, Kimmel B, Weigang-Koehler K, Goebeler M, Birkmann J, et al. Tumor-promoting versus tumor-antagonizing roles of gammadelta $\mathrm{T}$ cells in cancer immunotherapy: results from a prospective phase I/II trial. JImmunother (2012) 35(2):205-13. doi:10.1097/CJI. 0b013e318245bble

25. Wilhelm M, Kunzmann V, Eckstein S, Reimer P, Weissinger F, Ruediger T, et al. Gammadelta $\mathrm{T}$ cells for immune therapy of patients with lymphoid malignancies. Blood (2003) 102(1):200-6. doi:10.1182/blood-2002-12-3665

26. Gertner-Dardenne J, Fauriat C, Vey N, Olive D. Immunotherapy of acute myeloid leukemia based on gammadelta T cells. Oncoimmunology (2012) 1(9):1614-6. doi:10.4161/onci.21512

27. Kobayashi H, Tanaka Y, Yagi J, Osaka Y, Nakazawa H, Uchiyama T, et al. Safety profile and anti-tumor effects of adoptive immunotherapy using gamma-delta T cells against advanced renal cell carcinoma: a pilot study. Cancer Immunol Immunother (2007) 56(4):469-76. doi:10.1007/s00262-006-0199-6

28. Bennouna J, Bompas E, Neidhardt EM, Rolland F, Philip I, Galea C, et al. Phase-I study of Innacell gammadelta, an autologous cell-therapy product highly enriched in gamma9delta2 T lymphocytes, in combination with IL-2, in patients with metastatic renal cell carcinoma. Cancer Immunol Immunother (2008) 57(11):1599-609. doi:10.1007/s00262-008-0491-8

29. Bennouna J, Levy V, Sicard H, Senellart H, Audrain M, Hiret S, et al. Phase I study of bromohydrin pyrophosphate (BrHPP, IPH 1101), a Vgamma9Vdelta2 $\mathrm{T}$ lymphocyte agonist in patients with solid tumors. Cancer Immunol Immunother (2010) 59(10):1521-30. doi:10.1007/s00262-010-0879-0

30. Nakajima J, Murakawa T, Fukami T, Goto S, Kaneko T, Yoshida Y, et al. A phase I study of adoptive immunotherapy for recurrent non-small-cell lung cancer patients with autologous gammadelta T cells. Eur J Cardiothorac Surg (2010) 37(5):1191-7. doi:10.1016/j.ejcts.2009.11.051

31. Sakamoto M, Nakajima J, Murakawa T, Fukami T, Yoshida Y, Murayama T, et al. Adoptive immunotherapy for advanced non-small cell lung cancer using zoledronate-expanded gammadeltaTcells: a phase I clinical study. J Immunother (2011) 34(2):202-11. doi:10.1097/CJI.0b013e318207ecfb

32. Nicol AJ, Tokuyama H, Mattarollo SR, Hagi T, Suzuki K, Yokokawa K, et al. Clinical evaluation of autologous gamma delta $\mathrm{T}$ cell-based immunotherapy for metastatic solid tumours. Br J Cancer (2011) 105(6):778-86. doi:10.1038/ bjc. 2011.293

33. Chitadze G, Oberg HH, Wesch D, Kabelitz D. The ambiguous role of gammadelta T lymphocytes in antitumor immunity. Trends Immunol (2017) 38(9): 668-78. doi:10.1016/j.it.2017.06.004

34. Silva-Santos B, Serre K, Norell H. Gammadelta T cells in cancer. Nat Rev Immunol (2015) 15(11):683-91. doi:10.1038/nri3904

35. Kong Y, Cao W, Xi X, Ma C, Cui L, He W. The NKG2D ligand ULBP4 binds to TCRgamma9/delta2 and induces cytotoxicity to tumor cells through both TCRgammadelta and NKG2D. Blood (2009) 114(2):310-7. doi:10.1182/ blood-2008-12-196287

36. Bai L, Picard D, Anderson B, Chaudhary V, Luoma A, Jabri B, et al. The majority of CD1d-sulfatide-specific T cells in human blood use a semiinvariant Vdeltal TCR. Eur J Immunol (2012) 42(9):2505-10. doi:10.1002/eji.201242531

37. Xu B, Pizarro JC, Holmes MA, McBeth C, Groh V, Spies T, et al. Crystal structure of a gammadelta T-cell receptor specific for the human MHC class I homolog MICA. Proc Natl Acad Sci U S A (2011) 108(6):2414-9. doi:10.1073/ pnas. 1015433108

38. Yin S, Zhang J, Mao Y, Hu Y, Cui L, Kang N, et al. Vav1-phospholipase C-gammal (Vav1-PLC-gamma1) pathway initiated by $\mathrm{T}$ cell antigen receptor (TCRgammadelta) activation is required to overcome inhibition by ubiquitin ligase Cbl-b during gammadeltaT cell cytotoxicity. J Biol Chem (2013) 288(37):26448-62. doi:10.1074/jbc.M113.484600

39. Toutirais O, Cabillic F, Le Friec G, Salot S, Loyer P, Le Gallo M, et al. DNAX accessory molecule-1 (CD226) promotes human hepatocellular carcinoma cell lysis by Vgamma9Vdelta2 T cells. Eur J Immunol (2009) 39(5):1361-8. doi:10.1002/eji.200838409

40. von Lilienfeld-Toal M, Nattermann J, Feldmann G, Sievers E, Frank S, Strehl J, et al. Activated gammadelta $\mathrm{T}$ cells express the natural cytotoxicity receptor natural killer p 44 and show cytotoxic activity against myeloma cells. Clin Exp Immunol (2006) 144(3):528-33. doi:10.1111/j.1365-2249.2006.03078.x

41. Bhagat G, Naiyer AJ, Shah JG, Harper J, Jabri B, Wang TC, et al. Small intestinal CD8+TCRgammadelta+NKG2A+ intraepithelial lymphocytes have attributes of regulatory cells in patients with celiac disease. J Clin Invest (2008) 118(1):281-93. doi:10.1172/JCI30989

42. Viale M, Ferrini S, Bacigalupo A. TCR gamma/delta positive lymphocytes after allogeneic bone marrow transplantation. Bone Marrow Transplant (1992) 10(3):249-53.

43. Yabe M, Yabe H, Hattori K, Hinohara T, Morimoto T, Kato S, et al. Transition of $\mathrm{T}$ cell receptor gamma/delta expressing double negative (CD4-/CD8-) lymphocytes after allogeneic bone marrow transplantation. Bone Marrow Transplant (1994) 14(5):741-6.

44. Cela ME, Holladay MS, Rooney CM, Richardson S, Alexander B, Krance RA, et al. Gamma delta $\mathrm{T}$ lymphocyte regeneration after $\mathrm{T}$ lymphocyte-depleted bone marrow transplantation from mismatched family members or matched unrelated donors. Bone Marrow Transplant (1996) 17(2):243-7.

45. Godder KT, Henslee-Downey PJ, Mehta J, Park BS, Chiang KY, Abhyankar S, et al. Long term disease-free survival in acute leukemia patients recovering with increased gammadelta $\mathrm{T}$ cells after partially mismatched related donor bone marrow transplantation. Bone Marrow Transplant (2007) 39(12):751-7. doi:10.1038/sj.bmt.1705650

46. Lamb LS Jr, Gee AP, Hazlett LJ, Musk P, Parrish RS, O’Hanlon TP, et al. Influence of $\mathrm{T}$ cell depletion method on circulating gammadelta $\mathrm{T}$ cell reconstitution and potential role in the graft-versus-leukemia effect. Cytotherapy (1999) 1(1):7-19. doi:10.1080/0032472031000141295

47. Lamb LS Jr, Henslee-Downey PJ, Parrish RS, Godder K, Thompson J, Lee C, et al. Increased frequency of TCR gamma delta $+\mathrm{T}$ cells in disease-free survivors following $\mathrm{T}$ cell-depleted, partially mismatched, related donor bone marrow transplantation for leukemia. J Hematother (1996) 5(5):503-9. doi:10.1089/scd.1.1996.5.503

48. Ruggeri L, Capanni M, Urbani E, Perruccio K, Shlomchik WD, Tosti A, et al. Effectiveness of donor natural killer cell alloreactivity in mismatched hematopoietic transplants. Science (2002) 295(5562):2097-100. doi:10.1126/ science. 1068440

49. Pende D, Marcenaro S, Falco M, Martini S, Bernardo ME, Montagna D, et al. Anti-leukemia activity of alloreactive NK cells in KIR ligand-mismatched haploidentical HSCT for pediatric patients: evaluation of the functional role of activating KIR and redefinition of inhibitory KIR specificity. Blood (2009) 113(13):3119-29. doi:10.1182/blood-2008-06-164103

50. Perko R, Kang G, Sunkara A, Leung W, Thomas PG, Dallas MH. Gamma delta $\mathrm{T}$ cell reconstitution is associated with fewer infections and improved event-free survival after hematopoietic stem cell transplantation for pediatric leukemia. Biol Blood Marrow Transplant (2015) 21(1):130-6. doi:10.1016/j. bbmt.2014.09.027

51. Hirokawa M, Horiuchi T, Kawabata Y, Kitabayashi A, Miura AB. Reconstitution of gammadelta $\mathrm{T}$ cell repertoire diversity after human allogeneic hematopoietic cell transplantation and the role of peripheral expansion of mature T cell population in the graft. Bone Marrow Transplant (2000) 26(2):177-85. doi:10.1038/sj.bmt.1702478

52. Ravens S, Schultze-Florey C, Raha S, Sandrock I, Drenker M, Oberdorfer L, et al. Human gammadelta $\mathrm{T}$ cells are quickly reconstituted after stem-cell transplantation and show adaptive clonal expansion in response to viral infection. Nat Immunol (2017) 18(4):393-401. doi:10.1038/ni.3686

53. Aversa F, Terenzi A, Tabilio A, Falzetti F, Carotti A, Ballanti S, et al. Full haplotype-mismatched hematopoietic stem-cell transplantation: a phase II study in patients with acute leukemia at high risk of relapse. J Clin Oncol (2005) 23(15):3447-54. doi:10.1200/JCO.2005.09.117

54. Aversa F, Terenzi A, Carotti A, Velardi A, Latini P, Gambelunghe C, et al. T-cell depletion in allogeneic bone marrow transplantation for acute leukaemias. Bone Marrow Transplant (1989) 4(Suppl 4):69-72.

55. Moretta A, Bottino C, Vitale M, Pende D, Cantoni C, Mingari MC, et al. Activating receptors and coreceptors involved in human natural killer cell-mediated cytolysis. Annu Rev Immunol (2001) 19:197-223. doi:10.1146/ annurev.immunol.19.1.197

56. Moretta L, Locatelli F, Pende D, Marcenaro E, Mingari MC, Moretta A. Killer Ig-like receptor-mediated control of natural killer cell alloreactivity in haploidentical hematopoietic stem cell transplantation. Blood (2011) 117(3):764-71. doi:10.1182/blood-2010-08-264085

57. Pende D, Bottino C, Castriconi R, Cantoni C, Marcenaro S, Rivera P, et al. PVR (CD155) and nectin-2 (CD112) as ligands of the human DNAM-1 (CD226) activating receptor: involvement in tumor cell lysis. Mol Immunol (2005) 42(4):463-9. doi:10.1016/j.molimm.2004.07.028 
58. Bari R, Rujkijyanont P, Sullivan E, Kang G, Turner V, Gan K, et al. Effect of donor KIR2DL1 allelic polymorphism on the outcome of pediatric allogeneic hematopoietic stem-cell transplantation. J Clin Oncol (2013) 31(30):3782-90. doi:10.1200/JCO.2012.47.4007

59. Nguyen S, Dhedin N, Vernant JP, Kuentz M, Al Jijakli A, Rouas-Freiss N, et al. NK-cell reconstitution after haploidentical hematopoietic stem-cell transplantations: immaturity of NK cells and inhibitory effect of NKG2A override GvL effect. Blood (2005) 105(10):4135-42. doi:10.1182/blood2004-10-4113

60. Vago L, Forno B, Sormani MP, Crocchiolo R, Zino E, Di Terlizzi S, et al. Temporal, quantitative, and functional characteristics of single-KIR-positive alloreactive natural killer cell recovery account for impaired graft-versusleukemia activity after haploidentical hematopoietic stem cell transplantation. Blood (2008) 112(8):3488-99. doi:10.1182/blood-2007-07-103325

61. Locatelli F, Bauquet A, Palumbo G, Moretta F, Bertaina A. Negative depletion of alpha/beta+ T cells and of CD19+ B lymphocytes: a novel frontier to optimize the effect of innate immunity in HLA-mismatched hematopoietic stem cell transplantation. Immunol Lett (2013) 155(1-2):21-3. doi:10.1016/j. imlet.2013.09.027

62. Schumm M, Lang P, Bethge W, Faul C, Feuchtinger T, Pfeiffer M, et al. Depletion of T-cell receptor alpha/beta and CD19 positive cells from apheresis products with the CliniMACS device. Cytotherapy (2013) 15(10):1253-8. doi:10.1016/j.jcyt.2013.05.014

63. Airoldi I, Bertaina A, Prigione I, Zorzoli A, Pagliara D, Cocco C, et al. Gammadelta T-cell reconstitution after HLA-haploidentical hematopoietic transplantation depleted of TCR-alphabeta+/CD19+ lymphocytes. Blood (2015) 125(15):2349-58. doi:10.1182/blood-2014-09-599423

64. Balashov D, Shcherbina A, Maschan M, Trakhtman P, Skvortsova Y, Shelikhova L, et al. Single-center experience of unrelated and haploidentical stem cell transplantation with TCRalphabeta and CD19 depletion in children with primary immunodeficiency syndromes. Biol Blood Marrow Transplant (2015) 21(11):1955-62. doi:10.1016/j.bbmt.2015.07.008

65. Bertaina A, Merli P, Rutella S, Pagliara D, Bernardo ME, Masetti R, et al. HLAhaploidentical stem cell transplantation after removal of alphabeta+ $\mathrm{T}$ and B cells in children with nonmalignant disorders. Blood (2014) 124(5):822-6. doi:10.1182/blood-2014-03-563817

66. Locatelli F, Merli P, Pagliara D, Li Pira G, Falco M, Pende D, et al. Outcome of children with acute leukemia given HLA-haploidentical HSCT after alphabeta T-cell and B-cell depletion. Blood (2017) 130(5):677-85. doi:10.1182/ blood-2017-04-779769

67. Couzi L, Pitard V, Moreau JF, Merville P, Dechanet-Merville J. Direct and indirect effects of cytomegalovirus-induced gammadelta $\mathrm{T}$ cells after kidney transplantation. Front Immunol (2015) 6:3. doi:10.3389/fimmu.2015. 00003

68. Uccelli A, Moretta L, Pistoia V. Mesenchymal stem cells in health and disease. Nat Rev Immunol (2008) 8(9):726-36. doi:10.1038/nri2395

69. Caccamo N, Meraviglia S, Ferlazzo V, Angelini D, Borsellino G, Poccia F, et al. Differential requirements for antigen or homeostatic cytokines for proliferation and differentiation of human Vgamma9Vdelta2 naive, memory and effector T cell subsets. Eur J Immunol (2005) 35(6):1764-72. doi:10.1002/ eji.200525983

70. Dieli F, Poccia F, Lipp M, Sireci G, Caccamo N, Di Sano C, et al. Differentiation of effector/memory Vdelta2 $\mathrm{T}$ cells and migratory routes in lymph nodes or inflammatory sites. J Exp Med(2003) 198(3):391-7. doi:10.1084/jem.20030235

71. Willcox CR, Pitard V, Netzer S, Couzi L, Salim M, Silberzahn T, et al. Cytomegalovirus and tumor stress surveillance by binding of a human gammadelta $\mathrm{T}$ cell antigen receptor to endothelial protein C receptor. Nat Immunol (2012) 13(9):872-9. doi:10.1038/ni.2394

72. Knight A, Madrigal AJ, Grace S, Sivakumaran J, Kottaridis P, Mackinnon S, et al. The role of Vdelta2-negative gammadelta T cells during cytomegalovirus reactivation in recipients of allogeneic stem cell transplantation. Blood (2010) 116(12):2164-72. doi:10.1182/blood-2010-01-255166

73. Scheper W, Grunder C, Kuball J. Multifunctional gammadelta T cells and their receptors for targeted anticancer immunotherapy. Oncoimmunology (2013) 2(5):e23974. doi:10.4161/onci.23974

74. Bertaina A, Zorzoli A, Petretto A, Barbarito G, Inglese E, Merli P, et al. Zoledronic acid boosts gammadelta $\mathrm{T}$-cell activity in children receiving alphabeta(+) T and CD19(+) cell-depleted grafts from an HLA-haplo-identical donor. Oncoimmunology (2017) 6(2):e1216291. doi:10.1080/2162402X. 2016.1216291

Conflict of Interest Statement: The authors declare that the research was conducted in the absence of any commercial or financial relationships that could be construed as a potential conflict of interest.

The reviewer EP and handling Editor declared their shared affiliation.

Copyright (C) 2018 Pistoia, Tumino, Vacca, Veneziani, Moretta, Locatelli and Moretta. This is an open-access article distributed under the terms of the Creative Commons Attribution License (CC BY). The use, distribution or reproduction in other forums is permitted, provided the original author(s) and the copyright owner are credited and that the original publication in this journal is cited, in accordance with accepted academic practice. No use, distribution or reproduction is permitted which does not comply with these terms. 